Check for updates

Cite this: RSC Adv., 2017, 7, 51290

Received 8th October 2017

Accepted 30th October 2017

DOI: $10.1039 / c 7 r a 11069 c$

rsc.li/rsc-advances

\title{
Gaseous-phase flame retardant behavior of a multi-phosphaphenanthrene compound in a polycarbonate composite
}

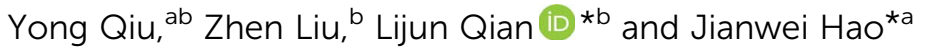

A multi-phosphaphenanthrene compound (TDBA) was incorporated into polycarbonate (PC) to prepare a flame retardant composite. TDBA improved the flame retardancy of the PC material effectively. The PC composite comprising $10 \mathrm{wt} \%$ TDBA passed the UL94 V-O level with a LOI value of $33.7 \%$. The incorporation of TDBA effectively inhibited the combustion intensity of the TDBA/PC composite via reducing the production of flammable methane and carbonyl-containing substances, suppressing the oxidative process of combustible pyrolysis products, and promoting the PC matrix to form large-scale smoke particles. All these were caused by releasing phosphaphenanthrene fragments, PO, and phenoxyl free radicals from pyrolyzed TDBA. As an additive-type flame retardant with multiple phosphaphenanthrene groups, TDBA was verified to exert its effect mainly in the gaseous phase during flame retarding of PC materials.
\end{abstract}

\section{Introduction}

With the rapid development of polymer science and technology, more and more polymer materials have been used to manufacture various lightweight or other featured products in a wide range of fields. ${ }^{1-6}$ As an important general engineering plastic, polycarbonate (PC) has also achieved great development in many manufacturing industries, including building material, automobile, electrical and electronic, and medicine industries. $^{\text {7-10 }}$ Especially for bisphenol-A type PC, its inherent flame retardancy makes most untreated bisphenol-A type PC meet the standard of the UL94 V-2 level. ${ }^{11}$ However, the need for higherlevel flame retardant PC materials is always the bottom-line standard of application. Therefore, to ensure and further promote the prosperous application of PC, developing novel and better flame retardant PC materials is indispensable and necessary. ${ }^{12,13}$

In recent years, great efforts have been invested into the research of flame retardant treatments on PC materials. ${ }^{\mathbf{1 4 - 1 7}}$ Undoubtedly, intermingling with additive-type flame retardants is the most convenient and workable strategy to improve the flame retardancy of PC materials. ${ }^{18,19}$ Based on this cognition, massive effective flame retardants have been developed and

${ }^{a}$ National Laboratory of Flame Retardant Materials, National Engineering and Technology Research Center of Flame Retardant Materials, School of Materials Science and Engineering, Beijing Institute of Technology, Beijing 100081, P. R. China.E-mail: hjw@bit.edu.cn

${ }^{b}$ Engineering Laboratory of Non-halogen Flame Retardants for Polymers, School of Materials Science and Mechanical Engineering, Beijing Technology and Business University, Beijing 100048, P. R. China.E-mail: qianlj@th.btbu.edu.cn applied in flame retarding PC materials, including halogencontaining, ${ }^{20}$ sulphonate-containing, ${ }^{21,22}$ organosilicon-containing, ${ }^{23}$ phosphorus-containing compounds, ${ }^{24}$ inorganic additives, ${ }^{25}$ and nanomaterials. ${ }^{26,27}$ Recently, as a promising intermediate in developing novel halogen-free flame retardants, 9,10-dihydro-9-oxa-10-phosphaphenanthrene 10-oxide (DOPO) have been frequently used to synthesize effective and efficient phosphaphenanthrene-containing flame retardant additives for various polymer materials. ${ }^{28-33}$ And some similar works have also suggested that the addition of phosphaphenanthrenecontaining additive indeed improved the flame retardancy of PC materials effectively. ${ }^{34}$ Hence, the research on the phosphaphenanthrene-containing compound flame retarding PC materials is worth further exploring and investigating.

In this thesis, an additive-type, four-arm star-shaped, and multi-phosphaphenanthrene flame retardant compound (TDBA, ${ }^{35}$ shown in Fig. 1) is looking forward to improve the flame retardancy of PC materials effectively due to its multiple phosphaphenanthrene groups (flame retardant segment, shown in Fig. 1). The limited oxygen index (LOI) measurement, vertical burning test, and cone calorimeter test were adopted to evaluate the flammability and combustion behavior of composites. Meanwhile, the thermogravimetry-Fourier transform infrared spectroscopy (TG-FTIR) analyzed the influence of TDBA on the decomposition of PC matrix, and also monitored the structural characteristic of evolved gases during TG procedure. Furthermore, the pyrolysis-gas chromatography/mass spectrometry (Py-GC/MS) analysis on PC composites was also adopted to reveal the influence of TDBA on the detailed pyrolysis products of PC matrix. Through above results and 


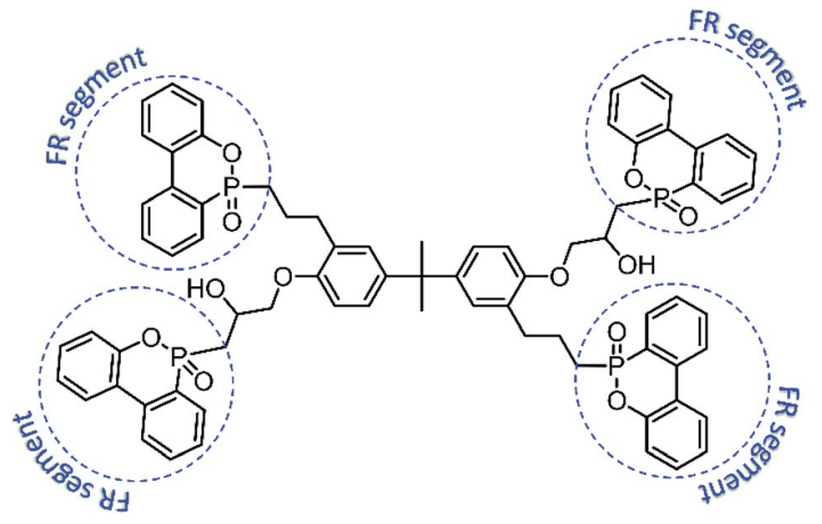

Fig. 1 Chemical structure of TDBA.

discussion, the action mode and mechanism of TDBA in flame retarding PC materials were sufficiently explored.

\section{Experimental}

\subsection{Materials}

PC (Wonderlite ${ }^{\circledR}$ PC-110) was purchased from Chi Mei Corporation. The light-yellow transparent glassy TDBA pieces were synthesized in our lab. ${ }^{35}$ TDBA has a glass transition process around $108{ }^{\circ} \mathrm{C}$ and an onset decomposition temperature above $300{ }^{\circ} \mathrm{C}$. Prior to processing, the PC pellets were dried at $120{ }^{\circ} \mathrm{C}$ for at least 4 hours under vacuum.

\subsection{Preparation of PC composites}

Firstly, TDBA/PC blends were compounded using an internal mixer at $230{ }^{\circ} \mathrm{C}$ for $8 \mathrm{~min}$ under a constant rotate speed of $60 \mathrm{r} \mathrm{min}{ }^{-1}$. Then, the blends were crushed into pieces via a plastic crusher. Finally, the specimens for LOI and UL94 level evaluation were molded utilizing a vertical injection-molding machine at $250{ }^{\circ} \mathrm{C}$, while the specimens for cone calorimeter test were prepared by compression molding at $235{ }^{\circ} \mathrm{C}$ with a pressure of $50 \mathrm{MPa}$. The specimens of Neat PC were directly molded using pre-dried PC pellets. The specific formulas for PC composites are listed in Table 1.

\subsection{Characterization}

2.3.1 LOI measurement. The LOI was measured using an FTT (Fire Testing Technology, UK) Dynisco LOI instrument

Table 1 Formulas of PC composites

\begin{tabular}{lllll}
\hline & & \multicolumn{2}{l}{ TDBA } & \\
\cline { 3 - 4 } Samples & PC $(\mathrm{g})$ & $(\mathrm{g})$ & $(\mathrm{wt} \%)$ & $\begin{array}{l}\text { Phosphorus content } \\
(\mathrm{wt} \%)\end{array}$ \\
\hline PC & 200 & - & - & - \\
$6 \%$ TDBA/PC & 188 & 12 & 6 & 0.58 \\
$8 \%$ TDBA/PC & 184 & 16 & 8 & 0.77 \\
$10 \%$ TDBA/PC & 180 & 20 & 10 & 0.96
\end{tabular}

according to ASTM D2863. The dimension of specimen was $100.0 \mathrm{~mm} \times 6.5 \mathrm{~mm} \times 3.2 \mathrm{~mm}$.

2.3.2 Vertical burning test. The UL94 flammability classification was determined using an FTT0082 UL94 flame chamber according to ASTM D 3801. The dimension of specimen was $125.0 \mathrm{~mm} \times 12.7 \mathrm{~mm} \times 3.2 \mathrm{~mm}$.

2.3.3 Cone calorimeter test. The detailed combustion behaviors were investigated using a FTT cone calorimeter according to ISO 5660 at an external heat flux of $50 \mathrm{~kW} \mathrm{~m}{ }^{-2}$. Every sample was tested at least twice. The dimension of specimen was $100 \mathrm{~mm} \times 100 \mathrm{~mm} \times 3 \mathrm{~mm}$.

2.3.4 TG-FTIR analysis. The thermogravimetric analysis was carried out on a STA 8000 simultaneous thermal analyzer produced by Perkin Elmer. The PC composite specimens were placed in an alumina crucible and heated from $50{ }^{\circ} \mathrm{C}$ up to $700{ }^{\circ} \mathrm{C}$ at a rate of $20^{\circ} \mathrm{C} \mathrm{min}{ }^{-1}$ under nitrogen $\left(\mathrm{N}_{2}\right)$ atmosphere. The thermal decomposition of TDBA was also evaluated in accordance with above procedure in $\mathrm{N}_{2}$ atmosphere. The realtime FTIR spectra of evolved gases during TG procedure were detected via a Frontier FTIR spectrometer produced by Perkin Elmer. The FTIR specimen cell and transfer line were both kept at $280{ }^{\circ} \mathrm{C}$.

2.3.5 Py-GC/MS analysis. The specific pyrolysis products of PC composites were monitored by Shimadzu GCMS-QP 2010 Plus GC-MS equipped with a PYR-4A pyrolyzer. The helium was utilized as carrier gas. The pyrolysis temperature was $500{ }^{\circ} \mathrm{C}$.

2.3.6 Differential scanning calorimetry (DSC). The glass transition behavior of neat PC and TDBA/PC samples were determined under $\mathrm{N}_{2}$ atmosphere via a Q20 differential scanning calorimeter produced by TA instruments. The thermal history was eliminated at $200{ }^{\circ} \mathrm{C}$ for $5 \mathrm{~min}$ and then cooling down to $40{ }^{\circ} \mathrm{C}$ at a rate of $20^{\circ} \mathrm{C} \mathrm{min}^{-1}$. After holding at $40{ }^{\circ} \mathrm{C}$ for $5 \mathrm{~min}$, the specimen was heated from $40{ }^{\circ} \mathrm{C}$ up to $200^{\circ} \mathrm{C}$ at a rate of $20{ }^{\circ} \mathrm{C} \mathrm{min}^{-1}$.

\section{Results and discussion}

\subsection{LOI measurement and vertical burning test}

Generally, LOI measurement and vertical burning test, as two basic flammability evaluation methods, are frequently adopted to investigate the effect of additives on improving flame retardancy of materials. Through above two tests, the LOI and UL94 levels of PC composites were evaluated and listed in Table 2. Meanwhile, the photos of the relevant PC composite specimens after LOI measurement and vertical burning test are shown in Fig. 2.

Apparently, the addition of TDBA effectively inhibited the combustion of PC materials. Only 6 wt $\%$ TDBA elevated the LOI value of composite from $26.2 \%$ in neat $\mathrm{PC}$ to $30.3 \%$ in $6 \%$ TDBA/PC. With increasing TDBA loading from $6 \mathrm{wt} \%$ to $10 \mathrm{wt} \%$, the LOI of TDBA/PC composite was gradually further elevated to higher values. In 10\% TDBA/PC, the highest LOI value $33.7 \%$ was achieved within this research range. Meanwhile, the results of vertical burning test also demonstrated that the incorporation of TDBA contributed greatly to shortening the afterburning time of TDBA/PC composite after both of the first and second flame applications. And, also in the case of $10 \mathrm{wt} \%$ loading, 
Table 2 LOI value and UL94 level of PC composites

Vertical burning test

Afterburning time

\begin{tabular}{llrrrrr}
\cline { 3 - 5 } Samples & LOI $(\%)$ & \multicolumn{1}{c}{$t_{1}(\mathrm{~s})$} & & UL94 level & Dripping & Ignition \\
\hline PC & $26.2 \pm 0.1$ & $27.3 \pm 2.0$ & $8.4 \pm 3.5$ & V-2 & Yes & Yes \\
$6 \%$ TDBA/PC & $30.3 \pm 0.2$ & $5.9 \pm 2.4$ & $4.2 \pm 1.8$ & V-2 & Yes & Yes \\
$8 \%$ TDBA/PC & $31.3 \pm 0.2$ & $0.9 \pm 0.5$ & $1.2 \pm 0.2$ & V-2 & Yes & Yes
\end{tabular}

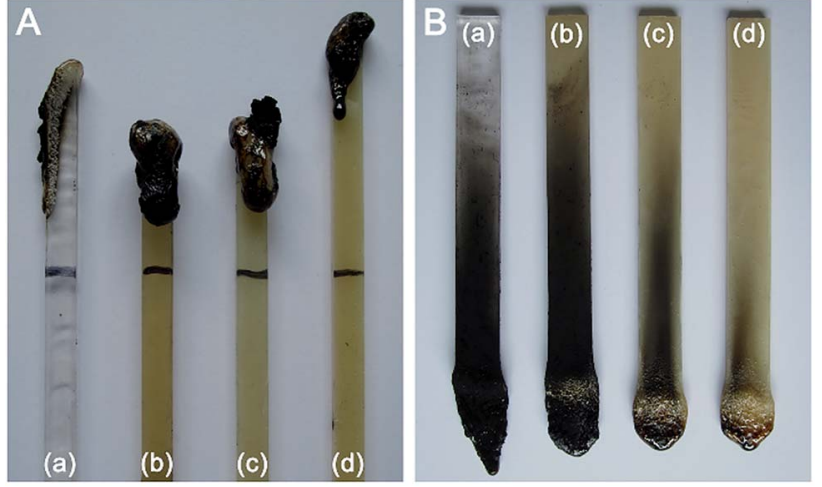

Fig. 2 Photos of the PC composite specimens after LOI measurement (A) and vertical burning test (B). (a) PC, (b) 6\% TDBA/PC, (c) $8 \%$ TDBA/ PC, and (d) $10 \%$ TDBA/PC.

TDBA endowed PC material passed UL94 V-0 level. Besides, the photos of LOI and vertical burning test residue suggested that TDBA worked on the combustion of PC material mainly via gaseous-phase action, rather than condensed-phase one. Because less char residue was reserved on the burnt specimen, as shown in Fig. 2. The remarkable flame retardant performance of TDBA-containing composites in LOI and UL94 level evaluation indicates that, TDBA is capable to improve the flame retardancy of PC materials effectively.

\subsection{Cone calorimeter test}

Unlike the simple and direct results in LOI and vertical burning tests, as a lab-scale testing method, cone calorimeter test is proceeded to monitor the combustion parameters of specimen comprehensively under specific external heat flux, such as heat release rate (HRR), smoke production, carbon monoxide yield (COY), carbon dioxide yield $\left(\mathrm{CO}_{2} \mathrm{Y}\right)$, and so on. Through analyzing relevant combustion parameters, the effect and mode of flame retardant action can be well evaluated and revealed. For this purpose, the PC composites were measured via cone colorimeter under an external heat flux of $50 \mathrm{~kW} \mathrm{~m}^{-2}$. The corresponding parameters are listed in Table 3.

As shown in Fig. 3, the addition of TDBA suppressed the combustion of TDBA/PC composites to a relatively weaker intensity with relatively lower peak of HRR (pk-HRR), compared with that of neat PC. And the pk-HRR of TDBA/PC composites reduced along with the increase of TDBA loadings. Especially, in the case of $10 \%$ TDBA/PC, its pk-HRR reduced by $29.2 \%$ than that of neat PC. Meanwhile, the early HRR within $100 \mathrm{~s}$ discloses that, the incorporation of TDBA shortened the time to ignition (TTI) of TDBA/PC composites. And roughly, the more TDBA was introduced in composite, the faster ignition of TDBA/PC composite happened. Besides, unlike the obvious single-peak HRR curve of neat PC, the fluctuant HRR platform around pkHRR in TDBA/PC composite reveals that TDBA suppressed combustion of composite to a lower-intensity and roughlystable combustion state. Hence, the effect of TDBA on HRR exposes that TDBA worked on the combustion of PC matrix starting from initial ignition to sufficient burning stages.

According to the mass loss curves of PC composites shown in Fig. 4, it can be observed that, compared with that of neat PC, the slope of the mass loss curves in TDBA/PC composites were all nearly equal to that of neat PC after ignition, although TDBA induced PC matrix to decompose in advance. It reveals that the mass loss rate of burning TDBA/PC composite was similar to that of burning neat PC, signifying that TDBA contributed less to the barrier effect of matrix residue on the volatiles release during combustion. Further, compared with that of neat PC, the much less residue retention of TDBA/PC composite even discloses that more decomposed volatiles were released into gaseous phase. Interestingly, compared with that of neat PC, the more mass of substances released from burning TDBA/PC composite resulted in lower total heat release (THR) instead. Especially, the THR of $10 \%$ TDBA/PC was obviously reduced by

Table 3 Combustion parameters collected in cone calorimetry test

\begin{tabular}{|c|c|c|c|c|c|c|c|}
\hline Samples & pk-HRR $\left(\mathrm{kW} \mathrm{m}^{-2}\right)$ & av-EHC (MJ kg $\left.{ }^{-1}\right)$ & $\mathrm{THR}\left(\mathrm{MJ} \mathrm{m}^{-2}\right)$ & $\operatorname{TSP}\left(\mathrm{m}^{2}\right)$ & av-COY $\left(\mathrm{kg} \mathrm{kg}^{-1}\right)$ & av-CO ${ }_{2} \mathrm{Y}\left(\mathrm{kg} \mathrm{kg}^{-1}\right)$ & Residue (wt\%) \\
\hline PC & $800 \pm 19$ & $32.5 \pm 0.4$ & $113 \pm 1$ & $32.0 \pm 1.5$ & $0.15 \pm 0.00$ & $2.81 \pm 0.05$ & $17.3 \pm 1.0$ \\
\hline $6 \%$ TDBA/PC & $643 \pm 10$ & $27.5 \pm 0.7$ & $104 \pm 4$ & $43.1 \pm 0.1$ & $0.21 \pm 0.01$ & $2.34 \pm 0.04$ & $15.6 \pm 0.5$ \\
\hline $10 \%$ TDBA/PC & $566 \pm 7$ & $24.2 \pm 0.5$ & $92 \pm 2$ & $49.6 \pm 0.4$ & $0.24 \pm 0.01$ & $2.07 \pm 0.02$ & $12.8 \pm 0.8$ \\
\hline
\end{tabular}




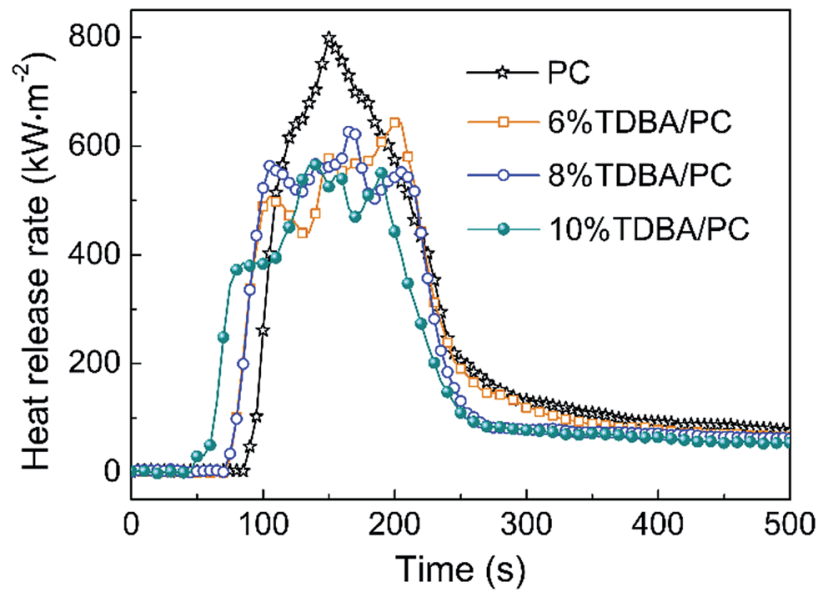

Fig. 3 HRR curves of PC composites in cone calorimeter test.

$18.58 \%$ than that of neat PC. These results reveals that TDBA suppressed the gaseous-phase combustion reaction of PC matrix.

In addition, the average effective heat of combustion (avEHC) listed in Table 3 also verifies the gaseous-phase flame retardant effect of TDBA in TDBA/PC composite. Observably, the av-EHC of TDBA/PC composites decreased gradually with the increase of TDBA loadings. Namely, the addition of TDBA forced burning composite to proceed more incomplete combustion. This result strongly proves the gaseous-phase flame-retardant effect of TDBA. Meanwhile, the total smoke production (TSP) curves shown in Fig. 5 also afford evidence to the increased incomplete combustion in burning TDBA/PC composite. Compared with that of neat PC, the dramatically increased TSP of TDBA/PC composite reveals that the burning TDBA containing composite produced much more large-scale fragments which were finally released as smoke particles, rather than further pyrolyzed and oxidized. Further, the slope of TSP in TDBA/PC composites was gradually elevated with the increase of TDBA loadings, indicating the more addition of TDBA promoted faster and more smoke production. As for the

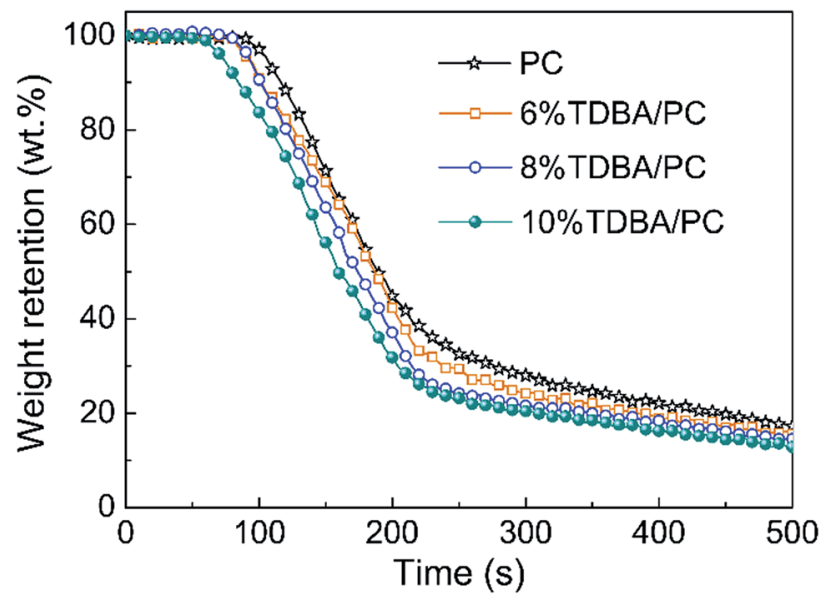

Fig. 4 Mass loss curves of PC composites in cone calorimeter test.

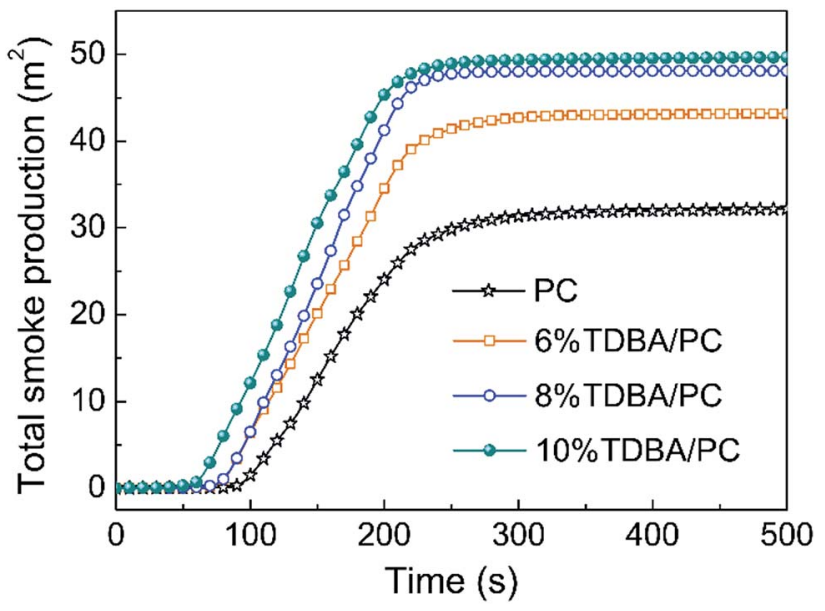

Fig. 5 TSP curves of PC composites in cone calorimeter test.

obviously increased average COY (av-COY) and moderately reduced average $\mathrm{CO}_{2} \mathrm{Y}\left(\mathrm{av}-\mathrm{CO}_{2} \mathrm{Y}\right)$ in TDBA/PC composites, it demonstrates that the incorporation of TDBA also suppressed the final oxidative process of combustible pyrolysis products distinctly. Above results firmly verify that the gaseous-phase flame retardant action of TDBA in burning TDBA/PC composites dominantly suppressed the combustion behaviour of composite, and then endowed PC materials with higher flame retardancy.

\subsection{Thermal analysis}

To further explore the influence of TDBA on the decomposition behavior of PC matrix, TDBA, neat PC, and TDBA/PC composites were all investigated via TG analyzer in $\mathrm{N}_{2}$ atmosphere. Accordingly, the corresponding TG curves are shown in Fig. 6, and some thermal decomposition data are listed in Table 4 .

Obviously, TDBA, neat PC, and TDBA/PC composites all show one-stage decomposition behavior. Compared with that of neat PC, the initial decomposition temperature $\left(T_{\mathrm{d}, 1 \%}\right)$ of TDBA/ PC composites reduced gradually with the increase of TDBA

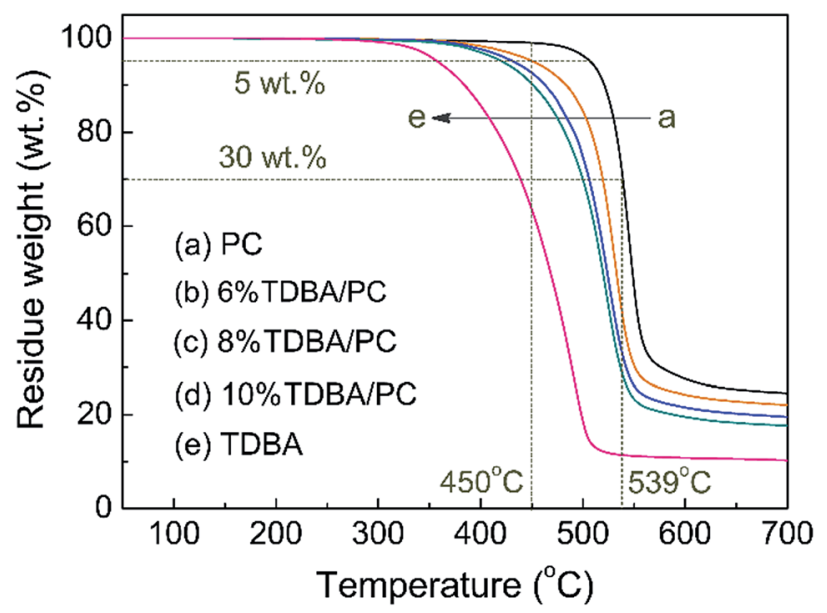

Fig. 6 TG curves of PC composites and TDBA in $\mathrm{N}_{2}$ atmosphere. 
Table 4 Thermal decomposition data of TDBA and PC composites

\begin{tabular}{|c|c|c|c|c|c|c|c|c|}
\hline Samples & $T_{\mathrm{d}, 1 \%}\left({ }^{\circ} \mathrm{C}\right)$ & $T_{\mathrm{d}, 5 \%}\left({ }^{\circ} \mathrm{C}\right)$ & $T_{\mathrm{d}, 30 \%}\left({ }^{\circ} \mathrm{C}\right)$ & $T_{\mathrm{d}, \max }\left({ }^{\circ} \mathrm{C}\right)$ & $R_{450^{\circ} \mathrm{C}}(\mathrm{wt} \%)$ & $R_{539^{\circ} \mathrm{C}}(\mathrm{wt} \%)$ & $R_{700^{\circ} \mathrm{C}}(\mathrm{wt} \%)$ & $T_{\mathrm{g}}\left({ }^{\circ} \mathrm{C}\right)$ \\
\hline $\mathrm{PC}$ & $450 \pm 2$ & $507 \pm 3$ & $539 \pm 4$ & $545 \pm 3$ & $99.0 \pm 0.1$ & $70.0 \pm 0.2$ & $24.5 \pm 0.3$ & $148 \pm 1.0$ \\
\hline $6 \%$ TDBA/PC & $380 \pm 4$ & $452 \pm 4$ & $519 \pm 5$ & $532 \pm 4$ & $95.2 \pm 0.2$ & $40.7 \pm 0.2$ & $22.0 \pm 0.2$ & $143 \pm 0.5$ \\
\hline $10 \%$ TDBA/PC & $356 \pm 3$ & $421 \pm 3$ & $500 \pm 4$ & $524 \pm 5$ & $90.3 \pm 0.2$ & $28.4 \pm 0.2$ & $17.6 \pm 0.3$ & $140 \pm 0.5$ \\
\hline TDBA & $308 \pm 1$ & $355 \pm 1$ & $439 \pm 1$ & $485 \pm 1$ & $63.6 \pm 0.1$ & $11.4 \pm 0.1$ & $10.3 \pm 0.1$ & $108 \pm 1.0$ \\
\hline
\end{tabular}

loadings. Moreover, with further increasing temperature, this earlier-decomposition phenomenon was sustained although the decomposition temperature gap between neat $\mathrm{PC}$ and TDBA/PC composite was narrowed gradually, like $T_{\mathrm{d}, 5 \%}$ and $T_{\mathrm{d}, 30 \%}$. Along this trend, in the aspect of the maximum decomposition rate temperature $\left(T_{\mathrm{d}, \max }\right)$, the difference between neat PC and TDBA/PC was obviously narrowed, and the content influence of TDBA was weaken greatly in TDBA/PC samples, especially between $8 \%$ TDBA/PC and 10\% TDBA/PC. It suggested that, TDBA worked more mainly on the early decomposition of PC matrix. In the aspect of residue retention at certain temperature, it can be observed that the residue retention at $450{ }^{\circ} \mathrm{C}\left(R_{450^{\circ} \mathrm{C}}\right)$ of $\mathrm{TDBA} / \mathrm{PC}$ composites correspondingly reduced by $3.8 \mathrm{wt} \%$ to $8.7 \mathrm{wt} \%$ than that of neat $\mathrm{PC}$, when TDBA loadings increased from $6 \mathrm{wt} \%$ to $10 \mathrm{wt} \%$. With further increasing temperature to $539{ }^{\circ} \mathrm{C}$, the difference in $R_{539^{\circ} \mathrm{C}}$ between neat PC and TDBA/PC composite was further enlarged to $29.3 \mathrm{wt} \%$ to $41.6 \mathrm{wt} \%$ along with TDBA loadings increasing from $6 \mathrm{wt} \%$ to $10 \mathrm{wt} \%$. Combining the decomposition of TDBA alone, it can be observed that the mass loss of incorporated TDBA was far less than the mass loss gap between neat PC and TDBA/PC composite at both $450{ }^{\circ} \mathrm{C}$ and $539{ }^{\circ} \mathrm{C}$. Through above parallel comparisons separately in temperature and residue retention, it can be concluded that TDBA induced PC matrix to decompose earlier and more. As for the final residue retention, the cases of $R_{700^{\circ} \mathrm{C}}$ in neat PC and TDBA/PC composites were well in accordance with the trend of those in cone calorimeter tests. Hence, it can be concluded that TDBA promoted the decomposition of PC matrix, resulting in more mass of substances released into gaseous phase.

The DSC evaluation was also carried out to explore the influence of TDBA on the thermal deformation property of PC material. As listed in Table 4, TDBA has a relatively lower glass transition temperature $\left(T_{\mathrm{g}}\right)$ around $108{ }^{\circ} \mathrm{C}$, compared with that of neat PC. Fortunately, the incorporation of TDBA only slightly decreased the $T_{\mathrm{g}}$ of TDBA/PC composite by $5{ }^{\circ} \mathrm{C}$ to $8{ }^{\circ} \mathrm{C}$ with TDBA loadings increasing from $6 \mathrm{wt} \%$ to $10 \mathrm{wt} \%$. It signifies that the addition of TDBA will not influence much on the upperlimit operating temperature of PC materials.

\subsection{FTIR analysis on the evolved gases}

To clarify the structural messages of pyrolysis products during thermal decomposition procedure, the evolved gases from decomposing neat PC and 10\% TDBA/PC were analyzed via realtime FTIR spectra. Fig. 7 gives out the FTIR spectra of the
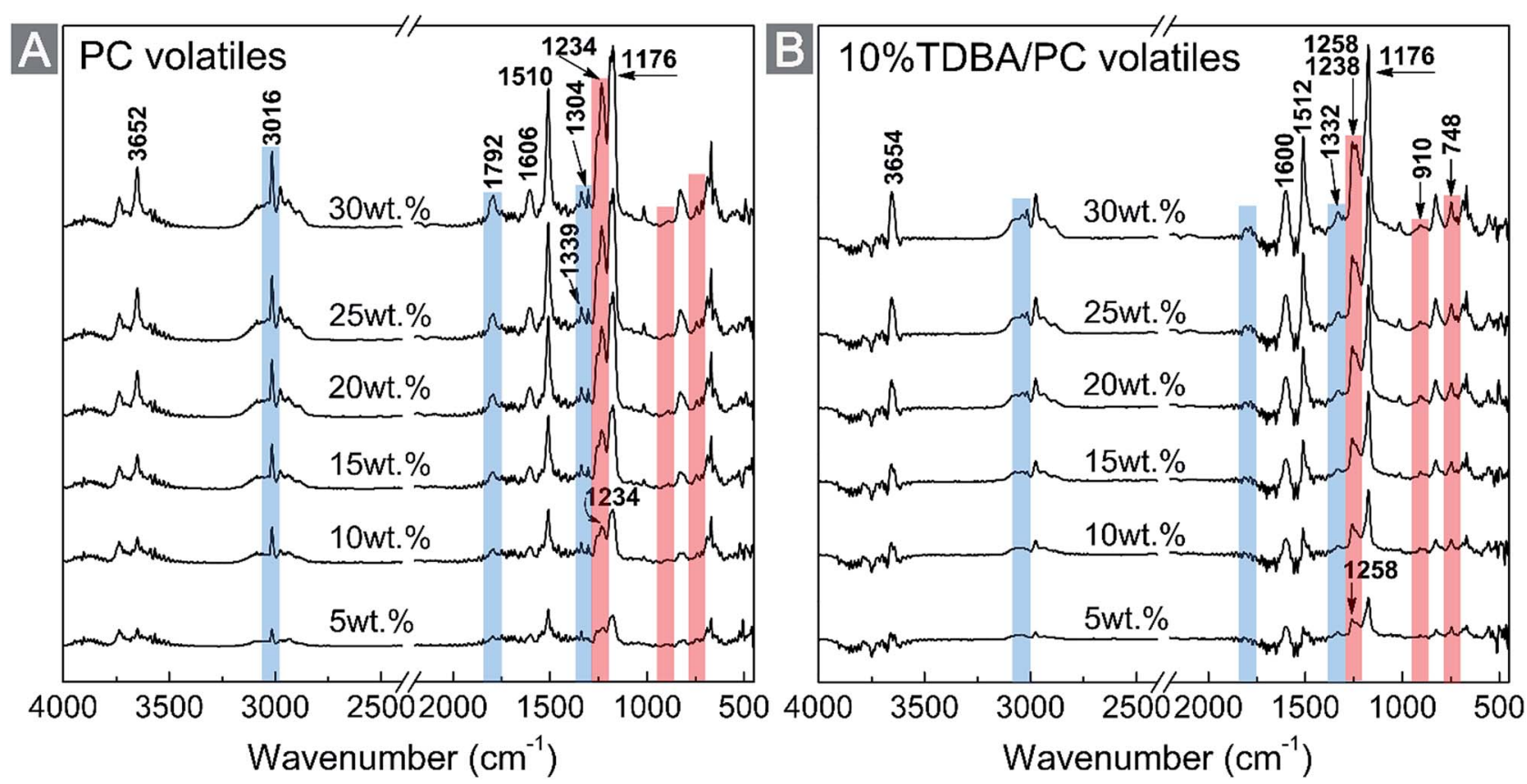

Fig. 7 FT-IR spectra of the evolved gases at different mass loss during TG procedure. (A) Neat PC; (B) 10\% TDBA/PC. 
evolved gases from decomposing neat PC and 10\% TDBA/PC at $5 \mathrm{wt} \%, 10 \mathrm{wt} \%, 15 \mathrm{wt} \%, 20 \mathrm{wt} \%, 25 \mathrm{wt} \%$, and $30 \mathrm{wt} \%$ mass loss nodes, respectively. As shown in Fig. 7(A), besides the cut wavenumber range, the methane $\left(\mathrm{CH}_{4}, \sim 3016 \mathrm{~cm}^{-1}\right.$ and $\left.\sim 1304 \mathrm{~cm}^{-1}\right)$, phenol derivatives $\left(\sim 3652 \mathrm{~cm}^{-1}\right.$ for $\mathrm{C}_{\text {aromatic }}-\mathrm{OH}$, $\sim 1603 \mathrm{~cm}^{-1}$ for $\mathrm{C}_{\text {aromatic }}=\mathrm{C}_{\text {aromatic }}, \sim 1511 \mathrm{~cm}^{-1}$ for $\mathrm{C}_{\text {aromatic }}{ }^{-}$ $\mathrm{H}, \sim 1176 \mathrm{~cm}^{-1}$ for $\left.\mathrm{C}_{\text {aromatic }}-\mathrm{O}\right)$, and carbonyl-containing substances $\left(\sim 1792 \mathrm{~cm}^{-1}\right.$ for $\mathrm{C}=\mathrm{O}$, and $\sim 1236 \mathrm{~cm}^{-1}$ for $\mathrm{C}_{\text {carbonyl }}-\mathrm{O}$ ) were the dominating products of decomposing neat PC within $30 \mathrm{wt} \%$ mass loss. ${ }^{36,37}$ Among them, the flammable $\mathrm{CH}_{4}$ and carbonyl-containing substances supplied fuels for the combustion of PC materials.

Fortunately, as shown in Fig. 7(B), the addition of TDBA dramatically suppressed the production of $\mathrm{CH}_{4}$ and carbonylcontaining substances from decomposing 10\% TDBA/PC. And the suppressing effect on the production of $\mathrm{CH}_{4}$ was particularly obvious. Further, the emerging peaks at $\sim 1258 \mathrm{~cm}^{-1}$, $\sim 910 \mathrm{~cm}^{-1}$, and $\sim 748 \mathrm{~cm}^{-1}$ in Fig. 7(B) presented the existence of $\mathrm{P}=\mathrm{O}, \mathrm{P}-\mathrm{O}-\mathrm{C}_{\text {aromatic }}$ and ortho-disubstituted benzene, respectively. ${ }^{38,39}$ The appearance of these three peaks affords important evidences to the existence of phosphaphenanthrene segments in gaseous phase. Especially, the peaks of $\mathrm{P}=\mathrm{O}$ and $\mathrm{P}-\mathrm{O}-\mathrm{C}_{\text {aromatic }}$ both belong to the key fragments of phosphaphenanthrene segments in flame retardant action. Also, the peak at $\sim 748 \mathrm{~cm}^{-1}$ still possibly responded to the pyrolysis products of the bi-substituted bisphenol-A segment in TDBA. Anyway, the FTIR results firmly verify the existence of the pyrolysis products from TDBA in gaseous phase, especially the clearly confirmed phosphaphenanthrene moieties. In addition, the remarkably enhanced peak of $\mathrm{C}_{\text {aromatic }}=\mathrm{C}_{\text {aromatic }}$ $\left(\sim 1600 \mathrm{~cm}^{-1}\right)$ in Fig. $7(\mathrm{~B})$ also reveals that the incorporation of TDBA promoted decomposing PC matrix to form more aromatic fragments. Therefore, it can be concluded that, incorporated TDBA not only reduced the formation of extremely flammable $\mathrm{CH}_{4}$ and carbonyl-containing volatiles, but also forced PC matrix to decompose into more large-scale aromatic fragments, which were very likely to be released as smoke particles finally.

\subsection{Py-GC/MS analysis on PC composites}

From flame retardancy evaluation to TG-FTIR analysis, the flame retardant effect and action of TDBA in PC materials were well discussed. In order to further clarify the influence of TDBA on the specific pyrolysis products of PC matrix, and also to uncover the specific functional fragments which potentially exerts flame retardant effect, the neat PC and 10\% TDBA/PC were still investigated via Py-GC/MS with a pyrolysis temperature at $500{ }^{\circ} \mathrm{C}$. Fig. 8 gives out the gas chromatogram of pyrolytic neat PC and 10\% TDBA/PC. The deduced structures of pyrolysis fragments are listed in Table 5.

As shown in Fig. 8(A), the pyrolysis of neat PC at $500{ }^{\circ} \mathrm{C}$ mainly produced two groups of fragments, shown as region (1) and (2). The fragments in region (1) belong to the semidecomposed phenolic products from bisphenol-A segment while the fragments in region (2) belong to the initialdecomposed and undecomposed bisphenol-A fragments. As for the case of $10 \% \mathrm{TDBA} / \mathrm{PC}$, its pyrolysis products can be divided into three parts. In region (1) and (2), the fragments of $10 \%$ TDBA/PC are almost the same as that in neat PC. Compared with the pyrolysis of neat PC, it can be concluded that the incorporation of TDBA inhibited PC matrix from pyrolyzing into semi- and initial-decomposed bisphenol-A fragments. Combined above discussions in cone calorimeter and TG-FTIR, these absent fragments should form large-scale aromatic particles, and be released as smoke finally. In region (3), the two moderate-intensity peaks represent methylsubstituted and vinyl-substituted phosphaphenanthrene fragments, respectively. With further pyrolysis, like the MS spectrum of vinyl-substituted phosphaphenanthrene shown in Fig. 8(B), series of PO free radicals $(\mathrm{m} / \mathrm{z}=215,139,63$, and 47$)$ should be produced and then be released from phosphaphenanthrene moieties. During combustion, these phosphaphenanthrene fragments, $\mathrm{PO}$, and phenoxyl free radicals can quench indispensable active free radicals in combustion, and then suppress and even terminate the combustion chain reaction of burning materials. Above quenching effect from TDBA
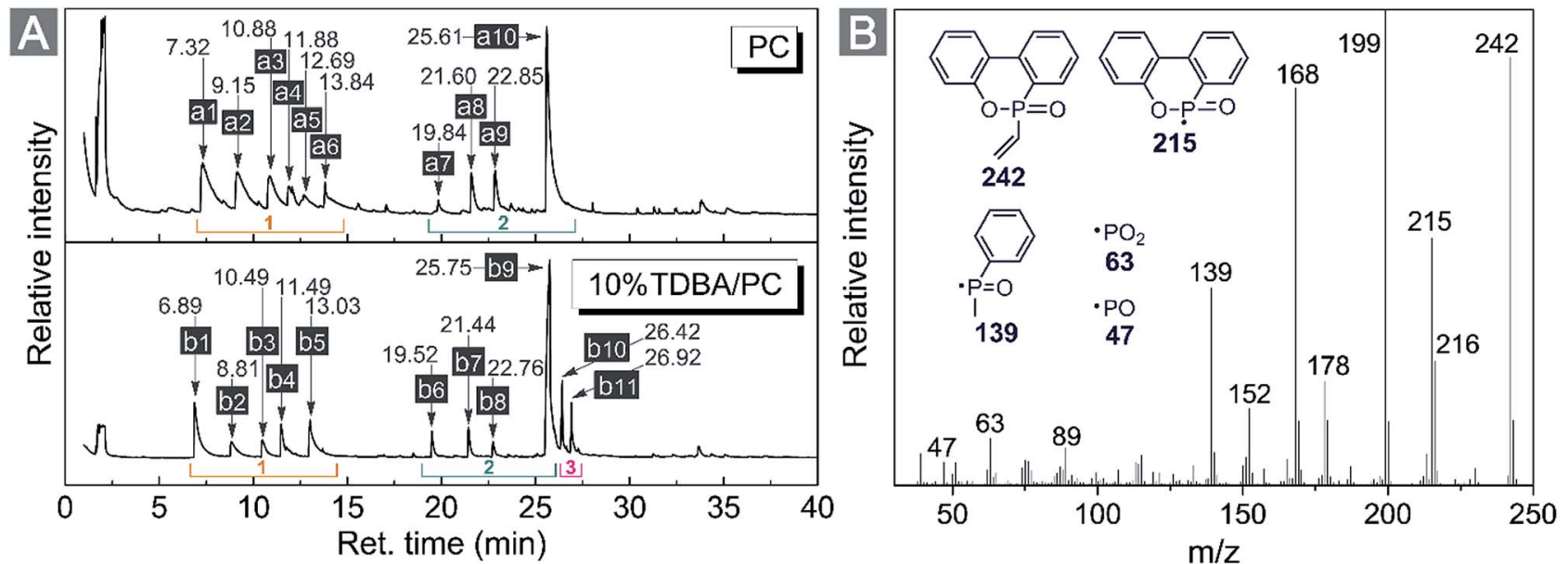

Fig. 8 (A) Gas chromatograms of neat PC and $10 \%$ TDBA/PC composite cracked at $500{ }^{\circ} \mathrm{C}$. (B) MS spectrum of vinyl-substituted phosphaphenanthrene fragment from 10\% TDBA/PC composite. 
Table 5 Deductive structures of pyrolysis fragments

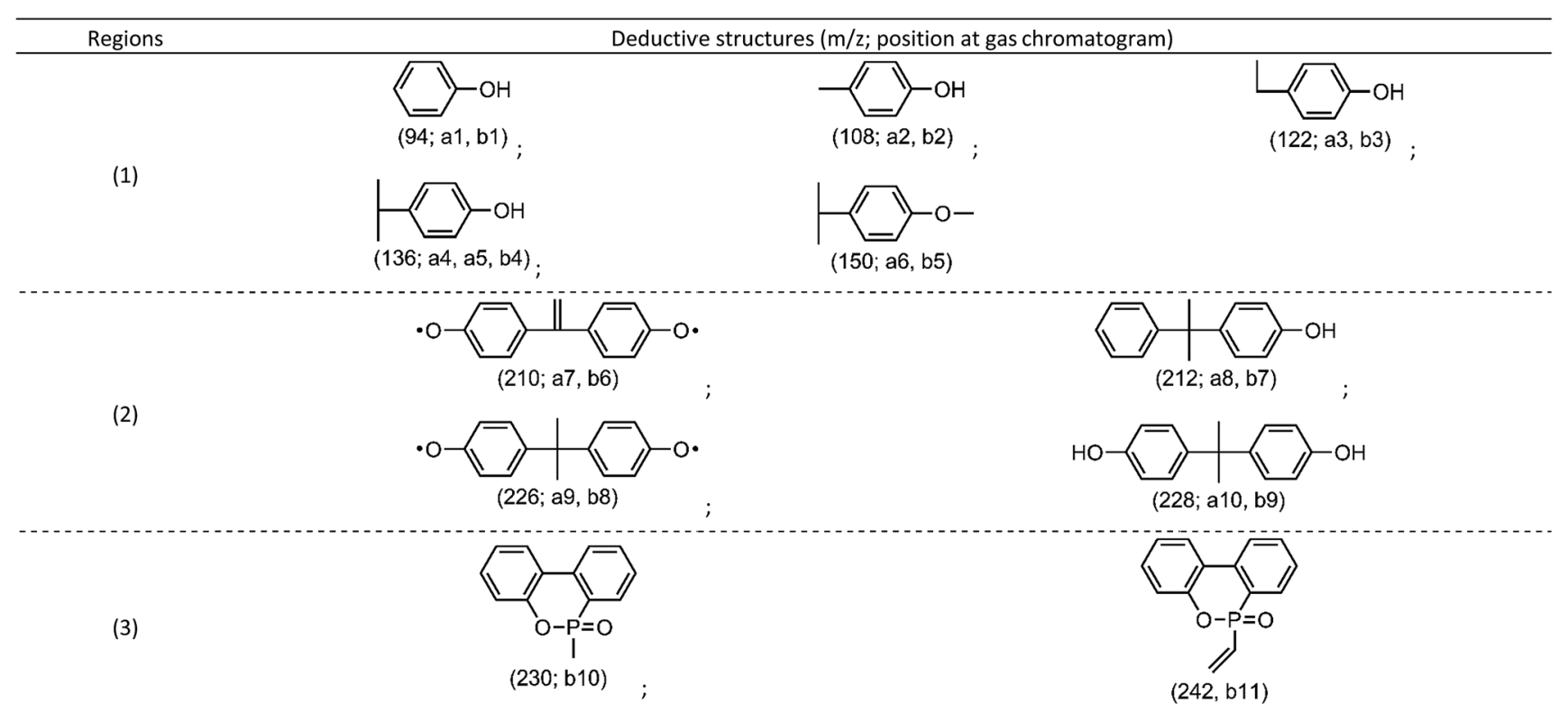

can exert outstanding gaseous-phase effect in suppressing the combustion of PC materials.

\section{Conclusion}

The application of the novel multi-phosphaphenanthrene compound TDBA in PC suggested that TDBA improved the flame retardancy of PC composite effectively. The PC composite comprising $10 \mathrm{wt} \%$ TDBA passed UL94 V-0 level with a LOI value of $33.7 \%$. During combustion, compared with that of neat PC, the incorporated TDBA not only reduced the production of extremely flammable $\mathrm{CH}_{4}$ and carbonyl-containing substances, but also suppressed the oxidative process of combustible pyrolysis products, and still promoted PC matrix to decompose earlier and faster with the formation of large-scale smoke particles. In addition, the phosphaphenanthrene fragments, PO, and phenoxyl free radicals, which were released from burning TDBA/PC composites, can quench indispensable active free radicals in combustion, and then inhibit and even terminate combustion chain reaction of burning composites. Through above gaseous-phase actions, TDBA inhibited the combustion behavior of burning PC composites, and endowed PC composites with good flame retardancy.

\section{Conflicts of interest}

There are no conflicts to declare.

\section{Acknowledgements}

This work was financially supported by National Nature Science Foundation of China (No. 21374003) and Key Project of Science and Technology Plan of Beijing Municipal Commission of
Education \& Beijing Municipal Natural Science Foundation (No. KZ201510011009).

\section{Notes and references}

1 A. Dasari, Z. Z. Yu, G. P. Cai and Y. W. Mai, Prog. Polym. Sci., 2013, 38, 1357-1387.

2 Q. Li, L. Chen, M. R. Gadinski, S. H. Zhang, G. Z. Zhang, H. Y. Li, E. Iagodkine, A. Haque, L. Q. Chen, T. N. Jackson and Q. Wang, Nature, 2015, 523, 576-579.

3 B. A. Khan, V. S. Chevali, H. N. Na, J. Zhu, P. Warner and H. Wang, Composites, Part B, 2016, 100, 10-18.

4 X. Liu, J. W. Hao and S. Gaan, RSC Adv., 2016, 6, 7474274756.

5 B. Joseph, A. George, S. Gopi, N. Kalarikkal and S. Thomas, Int. J. Pharm., 2017, 524, 454-466.

6 H. Y. Ma, P. A. Song and Z. P. Fang, Sci. China: Chem., 2011, 54, 302-313.

7 W. Chen, F. H. Meng, R. Cheng, C. Deng, J. Feijen and Z. Y. Zhong, J. Controlled Release, 2014, 190, 398-414.

8 E. Moretti, M. Zinzi and E. Belloni, Energ. Buildings, 2014, 70, 23-35.

9 G. Gedler, M. Antunes and J. I. Velasco, Composites, Part B, 2016, 92, 299-306.

10 N. Bagotia, V. Choudhary and D. K. Sharma, Composites, Part $B$, 2017, 124, 101-110.

11 S. Q. Fu, J. W. Guo, D. Y. Zhu, Z. Yang, C. F. Yang, J. X. Xian and X. Li, RSC Adv., 2015, 5, 67054-67065.

12 S. V. Levchik and E. D. Weil, Polym. Int., 2005, 54, 981-998. 13 L. Chen and Y. Z. Wang, Polym. Adv. Technol., 2010, 21, 1-26. 14 J. Feng, J. W. Hao and J. X. Du, ACS Symp. Ser., 2012, 1118, 113-122. 
15 S. N. Yang, G. P. Lv, Y. Liu and Q. Wang, Polym. Degrad. Stab., 2013, 98, 2795-2800.

16 J. Alongi, A. Di Blasio, F. Carosio and G. Malucelli, Polym. Degrad. Stab., 2014, 107, 74-81.

17 R. Heidar Pour, M. Soheilmoghaddam, A. Hassan and S. Bourbigot, Polym. Degrad. Stab., 2015, 120, 88-97.

18 S. V. Levchik and E. D. Weil, J. Fire Sci., 2006, 24, 137-151.

19 H. Vahabi, O. Eterradossi, L. Ferry, C. Longuet, R. Sonnier and J. M. Lopez-Cuesta, Eur. Polym. J., 2013, 49, 319-327.

20 D. Statler Jr, E. Stajduhar and R. K. Gupta, J. Fire Sci., 2008, 26, 331-350.

21 M. Colonna, C. Berti, E. Binassi, M. Fiorini, S. Sullalti, F. Acquasanta, S. Karanam and D. J. Brunelle, React. Funct. Polym., 2011, 71, 1001-1007.

22 S. J. Hou, Y. J. Zhang and P. K. Jiang, Polym. Degrad. Stab., 2016, 130, 165-172.

23 B. F. Cheng, X. M. Li, J. W. Hao and R. J. Yang, Polym. Degrad. Stab., 2016, 129, 47-55.

24 D. Lanzinger, S. Salzinger, B. S. Soller and B. Rieger, Ind. Eng. Chem. Res., 2015, 54, 1703-1712.

25 D. Q. Yi, H. X. Yang, M. Zhao, L. Huang, G. Camino, A. Frache and R. J. Yang, RSC Adv., 2017, 7, 5980-5988.

26 S. Suin, N. K. Shrivastava, S. Maiti and B. B. Khatua, Polym. Compos., 2016, 37, 199-212.

27 S. C. Moon, J. Y. Kim and B. T. Oh, Polym. Eng. Sci., 2014, 54, 1289-1299.
28 L. J. Qian, L. J. Ye, Y. Qiu and S. R. Qu, Polymer, 2011, 52, 5486-5493.

29 M. J. Xu, G. R. Xu, Y. Leng and B. Li, Polym. Degrad. Stab., 2016, 123, 105-114.

30 L. J. Qian, Y. Qiu, N. Sun, M. L. Xu, G. Z. Xu, F. Xin and Y. J. Chen, Polym. Degrad. Stab., 2014, 107, 98-105.

31 L. J. Qian, Y. Qiu, J. Y. Wang and W. Xi, Polymer, 2015, 68, 262-269.

32 Y. Qiu, L. J. Qian and W. Xi, RSC Adv., 2016, 6, 56018-56027.

33 Y. Cao, X. L. Wang, W. Q. Zhang, X. W. Yin, Y. Q. Shi and Y. Z. Wang, Ind. Eng. Chem. Res., 2017, 56, 5913-5924.

34 Z. Hu, L. Chen, B. Zhao, Y. Luo, D. Y. Wang and Y. Z. Wang, Polym. Degrad. Stab., 2011, 96, 320-327.

35 Y. Qiu, Z. Liu, L. J. Qian and J. W. Hao, J. Anal. Appl. Pyrolysis, 2017, 127, 23-30.

36 B. N. Jang and C. A. Wilkie, Polym. Degrad. Stab., 2004, 86, 419-430.

37 E. Wawrzyn, B. Schartel, M. Ciesielski, B. Kretzschmar, U. Braun and M. Döring, Eur. Polym. J., 2012, 48, 1561-1574.

38 B. Perret, B. Schartel, K. Stöß, M. Ciesielski, J. Diederichs, M. Döring, J. Krämer and V. Altstädt, Macromol. Mater. Eng., 2011, 296, 14-30.

39 E. Wawrzyn, B. Schartel, H. Seefeldt, A. Karrasch and C. Jäger, Ind. Eng. Chem. Res., 2012, 51, 1244-1255. 